\title{
SAHARAN AND ARABIAN DUST AEROSOLS: A COMPARATIVE CASE STUDY OF LIDAR RATIO
}

\author{
Carmen Córdoba-Jabonero $^{1 *}$, Ismail Sabbah ${ }^{2}$, Mar Sorribas ${ }^{1,3}$, José Antonio Adame ${ }^{1}$, Emilio \\ Cuevas $^{4}$, Faisal Al Sharifi ${ }^{5}$, Manuel Gil-Ojeda ${ }^{1}$ \\ ${ }^{I}$ Instituto Nacional de Técnica Aeroespacial (INTA), Atmospheric Research and Instrumentation Branch, \\ Torrejón de Ardoz, 28850-Madrid, Spain,*Email: cordobajc@inta.es \\ ${ }^{2}$ Department of Natural Sciences, College of Health Sciences, the Public Authority for Applied Education \\ and Training, Kuwait \\ ${ }^{3}$ Instituto Interuniversitario de Investigación del Sistema Tierra en Andalucía-Centro Andaluz de Medio \\ Ambiente (IISTA-CEAMA), Universidad de Granada (UGR), Granada, Spain \\ ${ }^{4}$ Agencia Estatal de Meteorología (AEMET), Izaña Atmospheric Research Centre, Santa Cruz de \\ Tenerife, Spain \\ ${ }^{5}$ Department of Environmental Sciences, College of Health Sciences, the Public Authority for Applied \\ Education and Training, Kuwait
}

\begin{abstract}
This work presents a first comparative study of the Lidar Ratio (LR) values obtained for dust particles in two singular dust-influenced regions: the Canary Islands (Spain, close to the African coast in the North Atlantic Ocean), frequently affected by Saharan dust intrusions, and the Kuwait area (Arabian Peninsula) as usually influenced by Arabian dust storms. Synergetic lidar and sun-photometry measurements are carried out in two stations located in these particular regions for that purpose. Several dusty cases were observed during 2014 in both stations and, just for illustration, two specific dusty case studies have been selected and analyzed to be shown in this work. In general, mean LR values of $54 \mathrm{sr}$ and $40 \mathrm{sr}$ were obtained in these studies cases for Saharan and Arabian dust particles, respectively. Indeed, these results are in agreement with other studies performed for dust particles arriving from similar desert areas. In particular, the disparity found in Saharan and Arabian dust LR values can be based on the singular composition of the suspended dust aerosols over each station. These results can be useful for CALIPSO extinction retrievals, where a single LR value (40 sr) is assumed for pure dust particles independently on the dust source region.
\end{abstract}

\section{INTRODUCTION}

The extinction-to-backscattering coefficient ratio (Lidar Ratio, LR) is an aerosol-type dependent parameter associated to the chemical composition, particle shape and aerosol size distribution. Hence, the LR estimation from lidar measurements is a crucial task in aerosol research, since this parameter can provide valuable information on optical/microphysical properties of aerosols. A special emphasis is devoted to dust, as shown by diverse published works [i.e., 1-11, among others]. Moreover, data from diverse observational platforms and techniques, as spaceborne instrumentation (CALIPSO/CALIOP and Aqua/MODIS) as ground-based aerosol networks (EARLINET and AERONET), and analysis from several models (BSC-DREAM, NAAPS, ...) have been used for assessment of the Aerosol Optical Depth (AOD), mainly, regarding the LR value used for dust aerosols. Hence, the single LR value assumed by CALIOP/CALIPSO (wwwcalipso.larc.nasa.gov) for pure dust (40 sr) is under discussion. Instead, a higher value (58 sr) is proposed by EARLINET (European Aerosol Lidar NETwork, www.earlinet.org) based on multi-year lidar measurements of Saharan dust intrusions over Europe [7, and references herein]. However, lower LR values are reported for Arabian dust by only a few works [i.e., 6; 8]. Currently, lidar measurements carried out in the Arabian Peninsula and surroundings are still scarce. 
The aim of this work is to show a first comparative analysis on LR values retrieved for dust particles present over two different dustinfluenced regions: the Canary Islands (Spain, close to the African coast in the North Atlantic Ocean), frequently affected by the arrival of Saharan dust intrusions, and the Kuwait area (Arabian Peninsula) as usually influenced by Arabian dust storms. Hence, dust observations were performed in particularly located lidar stations under both Saharan and Arabian dust influence in order to establish a long-term dust aerosol monitoring over these stations in the future. In this first step, two case studies of these dust observations are presented. Results can be useful for retrieving AOD from CALIPSO observations, despite a single LR value (40 sr) is assumed for pure dust particles independently on the dust source region.

\section{METHODOLOGY}

Lidar measurements in synergy with sunphotometry data are performed in two aerosol stations:

1) the Izaña observatory (IZO, $28.3^{\circ} \mathrm{N}$, $16.5^{\circ} \mathrm{W}, 2400 \mathrm{~m}$ a.s.1.), belonging to the Spanish Meteorological Agency (AEMET), is located at the Tenerife Island, in a pristine environment and representative of the Free Troposphere (FT) stations; hence, only pure dust particles are present under Saharan dust intrusion occurrence; and

2) the Kuwait station $\left(\mathrm{KW}, 29.3^{\circ} \mathrm{N}, 47.9^{\circ} \mathrm{E}\right.$, $40 \mathrm{~m}$ a.s.1.), belonging to the College of Health Sciences of Kuwait, is located in the Arabian Peninsula and usually influenced by dust storms. Their impact is particularly relevant in the Boundary Layer (BL) since they are transported by surface level northwesterly "Shamal" winds to Kuwait from Syria, Iraq and Jordan areas [12].

Synergetic measurements of both height-resolved lidar and columnar-integrated sun-photometry observations were performed in both areas. LR values are retrieved by using an elastic inversion procedure based on the AOD constraint and assuming the presence of pure dust particles. Details of this method are reported in [11].

\subsection{Tenerife instrumentation}

Lidar measurements for IZO site were carried out by a Micropulse Lidar v. 3 (MPL-3), within NASA/MPLNET (Micro Pulse Lidar NETwork, mplnet.gsfc.nasa.gov), located in the AEMET/Santa Cruz de Tenerife observatory (SCO, $40 \mathrm{~km}$ far from IZO, at $52 \mathrm{~m}$ a.s.l.). The MPL-3 is an elastic lidar, operated by the Instituto Nacional de Técnica Aeroespacial (INTA), with the following main features: highly-pulsed (2500 $\mathrm{Hz})$ and low-energy (10 $\mu \mathrm{J}$, max.) laser at $523 \mathrm{~nm}$, and Cassegrain-type telescope receiving system. It is a small, easy-handle system with coaxial configuration, high autonomy and low attendance, operational in full-time continuous mode $(24 \mathrm{~h}$ day-1/365 days year-1). Routine measurements (MPLNET settings) are $75-\mathrm{m}$ vertical resolution and 1-minute integrating time.

IZO is also a NASA/AERONET (AErosol RObotic NETwork, aeronet.gsfc.nasa.gov) site. Retrieved inversion products level 1.5 (Cloud Screened) and 2.0 (Quality-assured) used are the spectrally resolved Aerosol Optical Depth (AOD) and Ångström Exponent (AEx). In particular, the Cimel-318 500-nm channel data are used in correspondence to the closer wavelength to that of the MPL-3 laser (523 nm).

\subsection{Kuwait instrumentation}

A polarized Micropulse Lidar (P-MPL) has been recently installed in the Kuwait station, and routine measurements are performed from November 2013 to date for dust research. This system is similar to that MPL-3 together to polarization capabilities included. The main features are the same as those for the MPL-3 system, but the laser is at $532 \mathrm{~nm}$, and the receiving system is composed by a MatsukovCassegrain telescope with two polarization channels. Routine measurements are $30-\mathrm{m}$ vertical resolution and 30-second integrating time.

Sun-photometer data, mainly AOD values, are obtained with a portable sun-photometer (Microtops II).

\section{RESULTS}


Several dusty cases were observed during 2014 in both stations. In particular, one case study for each station was selected: 29 June for IZO site and 09 August for KW station, reporting AOD values of 0.35 and 0.46 , respectively (Note that IZO is placed at around $2400 \mathrm{~m}$ a.s.l.). LR values were retrieved for these dusty days, and preliminary results were analyzed.

Extinction profiles for Saharan and Arabian dust retrieved, respectively, from IZO MPL-3 and KW P-MPL measurements are shown in Figures 1 and 2 , respectively.

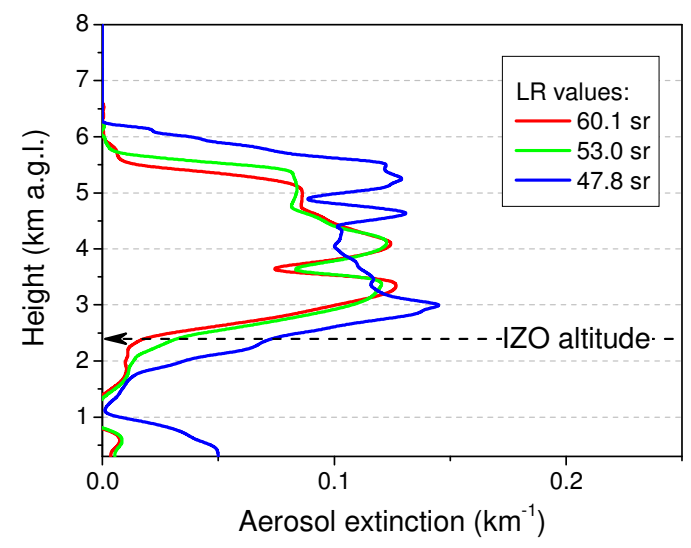

Figure 1. Saharan dust observed at IZO station: Aerosol extinction profiles derived from MPL-3 measurements performed on 29 June 2014 at several times (color lines).

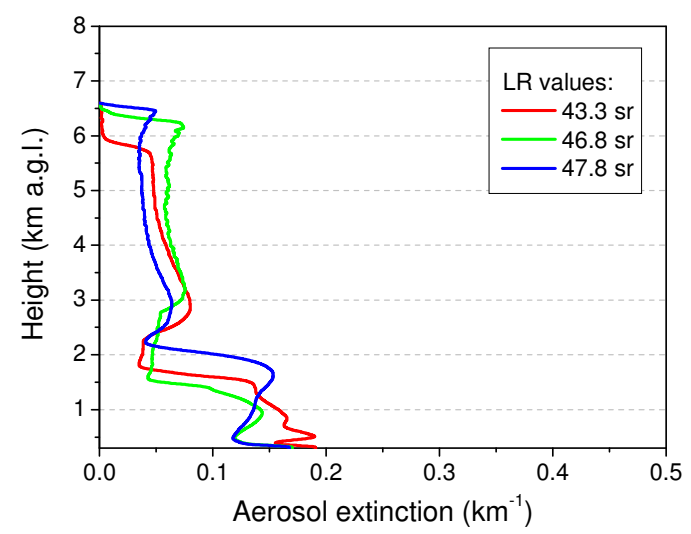

Figure 2. Arabian dust observed at KW station: Aerosol extinction profiles derived from P-MPL measurements performed on 09 August 2014 at several times (color lines).
Mean LR values of $54 \pm 5$ sr and $46 \pm 2$ sr are obtained for Saharan and Arabian dust particles, respectively, for these days (see Figs. 1 and 2). These preliminary results are in agreement with other LR values reported for dust in previous works [i.e., 6-8; 11] dependent on the desert dust source region. In addition, that observed disparity can be based on the singular composition of the suspended dust aerosols arriving from different desert areas, as reported in [6]. In that work an inverse relationship was found between LR and real refractive index, based on AERONET LR retrievals; in particular, Saharan dust presented a lower value of the real refractive index than that found for dust from the Arabian Middle East area; correspondingly, they obtained a higher LR (55 sr) for the Saharan dust than for Arabian dust (43 sr) [6]. Similar LR values were also derived by lidar measurements performed in Cyprus region for Arabian dust particles [8]. In general, it should be noted that results obtained in this work are specific for those particular cases analyzed.

\section{CONCLUSIONS}

A novel comparative analysis has been performed between LR values retrieved from MPL measurements carried out in two different dustinfluenced stations: $\mathrm{SCO}$ and $\mathrm{KW}$ sites, as affected, respectively, by Saharan and Arabian dust intrusions.

In this first study, one dusty case was selected for each station. Their derived LR values are in agreement with those obtained in other regions affected by both Saharan and Arabian dust arrivals, highlighting this way the diversity found in LR for dust particles arriving from different dust source regions. In particular, the LR assumed by CALIPSO for pure dust ( $40 \mathrm{sr}$ ) could be a correct value for dust over regions as Arabian Peninsula and surroundings. In addition, results can be relevant, indeed, for extinction retrievals from observations performed by future spaceborne elastic lidar instrumentation, as that aboard next ESA Sentinel and EarthCARE satellites.

Finally, a more extended dataset is to be analyzed in order to establish a long-term dust aerosol monitoring over these stations in the future. 
Hence, similarities and differences might be plausibly obtained in LR retrievals for dust by using a larger dataset for each station.

\section{ACKNOWLEDGEMENTS}

This work has been supported by both the Spanish Ministerio de Economía y Competitividad (MINECO) under grant CGL2011-24891 (AMISOC project) and the Kuwait Foundation for the Advancement of Sciences under project 20111401-01. We acknowledge NOAA Air Resources Laboratory (ARL) for the provision of the HYSPLIT model. Authors also thank the staff of both Tenerife and Kuwait stations for providing maintenance and support of all the instrumentation involved in this work.

\section{REFERENCES}

[1] Cattrall et al., 2005: Variability of aerosol and spectral lidar and backscatter and extinction ratios of key aerosol types derived from selected Aerosol Robotic Network locations, J. Geophys. Res., 110, D10S11, doi:10.1029/2004JD005124.

[2] Mona et al., 2006: Saharan dust intrusions in the Mediterranean area: Three years of Raman lidar measurements, J. Geophys. Res., 111, D16203, doi:10.1029/2005JD006569.

[3] Müller et al., 2007: Aerosol-type-dependent lidar ratios observed with Raman lidar, $J$. Geophys. Res., 112, D16202, doi:10.1029/2006JD008292.

[4] Córdoba-Jabonero et al., 2011: Synergetic monitoring of Saharan dust plumes and potential impact on surface: a case study of dust transport from Canary Islands to Iberian Peninsula, Atmos. Chem. Phys., 11, 3067-3091, doi:10.5194/acp-113067-2011.

[5] Campbell et al., 2012: Evaluating nighttime CALIOP $0.532 \mu \mathrm{m}$ aerosol optical depth and extinction coefficient retrievals, Atmos. Meas. Tech., 5, 2143-2160, doi:10.5194/amt-5-21432012.

[6] Schuster et al., 2012: Comparison of CALIPSO aerosol optical depth retrievals to AERONET measurements, and a climatology for the lidar ratio of dust, Atmos. Chem. Phys., 12, 7431-7452, doi:10.5194/acp-12-7431-2012.

[7] Amiridis et al., 2013: Optimizing CALIPSO Saharan dust retrievals, Atmos. Chem. Phys., 13, 12089-12106, doi:10.5194/acp-13-12089-2013.

[8] Mamouri et al., 2013: Low Arabian dust extinction-to-backscatter ratio, Geophys. Res. Lett., 40, 4762-4766, doi:10.1002/grl.50898.

[9] Omar et al., 2013: CALIOP and AERONET aerosol optical depth comparisons: One size fits none, J. Geophys. Res. Atmos., 118, 1-19, doi:10.1002/jgrd.50330.

[10] Tesche et al., 2013: Ground-based validation of CALIPSO observations of dust and smoke in the Cape Verde region, J. Geophys. Res. Atmos., 118, 2889-2902-, doi:10.1002/jgrd.50248.

[11] Córdoba-Jabonero, C., J. A. Adame, D. Grau, E. Cuevas and M. Gil-Ojeda, 2014: Lidar Ratio discrimination retrieval in a two-layer aerosol system from elastic lidar measurements in synergy with sun-photometry data, Proc. International Conference in Atmospheric Dust (DUST 2014), ProScience, 1, 243-248, published by Digilabs, DOI:10.14644/dust.2014.040.

[12] Sabbah, 2010: Impact of aerosol on air temperature in Kuwait, Atmospheric Res., 97, 303-314. 